conform to the rules, regulations and expectations associated with membership of any academic body. This means a commitment to professional excellence, research, audit, peer review and examination. It may mean that some of those who have contributed most to the development so far may not be able to reap the long term benefits.

DOMHNALL MACAULEY

\section{Osteoporosis and exercise}

Osteoporosis is a systemic skeletal disease characterised by low bone mass and microarchitectural deterioration of bone tissue with a consequent increase in bone fragility and susceptibly to fracture. It affects approximately $30 \%$ of women over the age of 50 and is a major health problem worldwide. It is increasing due to prolonged life expectancy and altered lifestyle. Fractures of the hip are associated with the highest mortality and morbidity. Twenty five per cent of those who have a hip fracture die within six months and $50 \%$ are incapacitated. The risk of developing a fragility fracture depends on the amount and strength of bone, and the rate at which bone is lost, and on falls. In women the major cause of bone loss and osteoporosis is oestrogen withdrawal. Hypogonadism is also a factor in male osteoporosis. Oestrogen increases trabecular bone, while testosterone affects cortical bone. Osteoporosis is a preventable disease. A large bone mass early in life protects against osteoporosis.

Bone is a living tissue that is continuously being turned over or remodelled during a cycle of resorption and bone formation which takes approximately 13 weeks. The rate of turnover is determined by hormonal and local factors. The turnover of trabecular bone is much greater and osteoporosis is more marked in trabecular bone, which is affected earlier than cortical bone.

Peak bone mass is generally achieved in early adulthood, being determined by sex, heredity, race, diet, exercise, and hormones. In females $50 \%$ of the bone mass is due to prepubertal growth, but only $10 \%$ in males. Physical activity is an important factor in determining peak bone mass but one must distinguish between the different forms of physical activity-weight bearing and non-weight-bearing.

The effect of exercise on bone mass is site specific. If the exercise involves mainly the lower limb, it may improve femoral neck bone density, but have no effect on the radius. It is essential to examine the specific region of interest, for example the neck of the femur and the lumbar spine, if you wish to determine the level of bone mineral density .

Physically active people have higher bone mineral densities than age matched controls. A meta-analysis of six trials showed that exercise reduced the incidence of hip fractures by $50 \%$. Skeletal fragility in the elderly can be traced to low peak bone mass attained during childhood and one of the factors is the level of physical activity undertaken during the developing years.
There is a relation between bone mass and activity. Women with osteoporotic fractures have a lower muscle mass and strength than age matched controls. Extremes of exercise, too little or excessive, both result in bone loss. Long periods of oestrogen deficiency during the early decades affect peak bone mass. Eating disorders such as anorexia nervosa, bulimia, excessive exercise induced amenorrhea, or excessive psychological stress and high levels of prolactin may all result in low oestrogen concentrations, resulting in an increased incidence of stress fractures and even osteoporosis in young females.

There has been an increase in eating disorders, particularly in the so called feminine sports such as gymnastics, synchronised swimming, ballet dancing, and weight category sports (light weight rowers). The combination of amenorrhoea, eating disorder, and osteoporosis is now known as the athletic triad. Unless patients are treated when they are young they will have major problems in later life.

Lack of physical activity is a risk factor for osteoporotic fractures. Immobilisation and prolonged bed rest produce a rapid bone loss, while exercise involving weight bearing has been shown to reduce bone loss and to increase bone mass. The optimal type and amount of physical activity that will prevent osteoporosis have not been established.

To increase bone mass and strength, exercise should involve loads of high magnitude and rate and should be dynamic in nature, with varied and diverse patterns of stress. Relatively few cycles of loading would be required so you do not have to exercise for long periods. It is very important to cross train and not rely on one exercise for both cardiovascular and osteoporosis prevention. The exercise must be enjoyable, as it will only be of benefit if it is continued and is a programme for life. Poor compliance is a major problem. Strategies to prevent falls are important. Exercise in elderly people may enhance mobility, muscle strength, and co-ordination.

The combination of exercise, calcium supplements, and hormone replacement therapy is the optimum treatment to prevent bone loss.

MOIRA O'BRIEN

Anatomy Department, Trinity College, Dublin,

Republic of Ireland

\title{
Medicolegal aspects of deliberate foul play in rugby union
}

Medico-legal principles, which have a common denominator, are applicable to all contact body sports, and particularly soccer, cricket, and rugby union. These principles are all interrelated, with a common thread protecting the doctor's patient, the lawyer's client, and the particular sport itself. These principles uphold the following. (1) The rule of law on the field of play should reflect the wider law, which never stops at the boundary or touchline. (2) The spirit of the game, identified as a Corinthian ethic of fair play, runs throughout. (3) The 
legal profession leans heavily and nearly always crucially on the available medical evidence when advising on injuries attributable to deliberate foul play in any sport. (4) Together we should persuade sports medical practitioners and others concerned with sport that the belief that all is fair in love and war, and in sport too, is criminally and civilly liable in court. (5) We should acknowledge the debt owed to sports medical practitioners who have possessed vision and understanding of their own particular sport, and emphasised the need to uphold the rule of law in the sport both on and of the field.

History illustrates the development of the problem. In Corinthians and cricketers ${ }^{1}$ I recount my second world war schoolboy's correspondence with a retired headmaster who had been the greatest centre forward of his day. In this correspondence, G O Smith produced an analysis of all aspects of football and cricket without any reference to our contemporary problems of violence and drugs. Later, in 1966, when the great Brazilian footballer Pele was brutally ejected from the World Cup in England by deliberate foul play, no action was taken by FIFA (soccer's world body). A further 11 years on, in 1977, a great Scottish referee, Norman Sanson, sent off Willy Duggan and Geoff Wheel for fighting in the Ireland-Wales rugby international at Cardiff. Sanson received little support, and Albert Ferasse, president of the French Federation, complained that Sanson was too strict to referee in the England $v$ France match a month later. The Rugby Football Union (RFU) did not reject the complaint and Sanson never refereed internationally again. That was the nadir for the rule of law in sport. A year later the tide turned.

In 1978, J P R Williams ${ }^{2}$ and John Davies and Terry Gibson $^{3}$ contributed crucial features in the last issue of the $B M F$ for December 1978. JPR explained how collapsing the scrum can damage the spine. Davies and Gibson ${ }^{3}$ showed that $30 \%$ of the injuries in their athletics injuries clinic were attributable to direct violent foul play. Finally, in that same year, a South Wales jury convicted a rugby player of assault occasioning actual bodily harm when he deliberately broke an opponent's jaw during a game. ${ }^{4}$ The principles applicable to deliberate, intentional, or reckless play had existed since 1878 . No one had bothered to apply them to rugby union for a whole century. Seven years later in 1985 they were first invoked against an international player, David Bishop, and since then they have surfaced regularly. Furthermore, the Criminal Injuries Compensation Board is ready to apply them. In one classical case a third XV player who had lost an eye in a line, the ophthalmic medical evidence, together with specialist evidence from a referee, a former Metropolitan Police Chief Superintendent, George Crawford, satisfied the Board to award a six figure sum in compensation. More recently, great attention has been paid to the civil claim for damages against a referee in a colts match establishing liability for negligence because of scrum collapse. At present the case is en route to the civil Court of Appeal but two aspects merit comment in any event. In a magical phrase coined out of the evidence before him, the judge explained that "the referee has a preventive mantle"; and on the eve of the reserved judgement, a different Court of Appeal, Criminal Division, confirmed a nine months custodial sentence imposed by Judge Baker at Kingston Crown Court on the Gloucester rugby captain who broke the jaw of a Rosslyn Park opponent during a game. After each judicial decision, the howls of outrage from the ill informed and cowardly custodians of the culture which wrongly believes that the law of the land-civil and criminal-does stop at a touchline or boundary, could be heard throughout the land. Finally, John King wrote to the Times after the 1991 FA Cup Final between Tottenham Hotspur and Nottingham Forest pointing out that the referee's failure to penalise Paul Gascoigne's initial foul on a Nottingham Forest defender was an act of negligence, because in effect it encouraged Gascoigne's second foul immediately afterwards, where he himself was injured though he could just as easily have injured the Nottingham Forest target of that second foul. Thus in conclusion, if doctors and lawyers can work together to identify and expose deliberate violent foul play with its devastating effect on our patients and clients, the barbarian in rugby can be offset by the Corinthian spirit in all sport.

EDWARD GRAYSON

President, British Association for Sport and Law 9-12 Bell Yard, London WC2

1 E Grayson. Corinthians and cricketers. London: The Naldrett Press, 1955. To be reissued in October 1996 by Yore Publications, Harefield

JPR Williams. Cervical spine injuries in rugby union football. BMF 1978; ii: 1747 .

3 Davies J, Gibson T. Injuries in rugby union football. BMF 1978;ii:175961

4 R V Billingshurst, 1978. Criminal Law Review 533. 